\title{
Shale Oil Value Enhancement Research
}

\author{
Quarterly Report \\ January 1 - March 31, 1996
}

Work Performed Under Contract No.: DE-AC21-93MC29240

For

U.S. Department of Energy

Office of Fossil Energy

Morgantown Energy Technology Center

P.O. Box 880

Morgantown, West Virginia 26507-0880

By

James W. Bunger and Associates

P. O. Box 520037

Salt Lake City, Utah 84152-0037

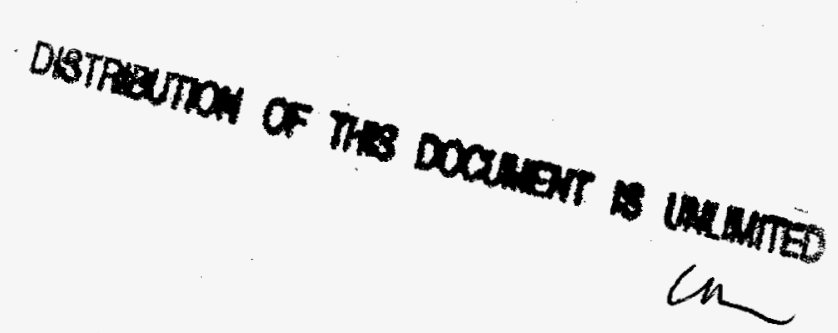




\section{DISCLAIMER}

Portions of this document may be illegible in electronic image products. Images are produced from the best available original document. 


\section{Disclaimer}

This report was prepared as an account of work sponsored by an agency of the United States Government. Neither the United States Government nor any agency thereof, nor any of their employees, makes any warranty, express or implied, or assumes any legal liability or responsibility for the accuracy, completeness, or usefulness of any information, apparatus, product, or process disclosed, or represents that its use would not infringe privately owned rights. Reference herein to any specific commercial product, process, or service by trade name, trademark, manufacturer, or otherwise does not necessarily constitute or imply its endorsement, recommendation, or favoring by the United States Government or any agency thereof. The views and opinions of authors expressed herein do not necessarily state or reflect those of the United States Government or any agency thereof. 


\section{Summary Management Report}

Activities during this quarter focused on (a) compound type analysis of shale oil and its extraction products, (b) thermal hydrodealkylation of the $>290^{\circ} \mathrm{C}$ polar fraction, and (c) economic analysis of the SPX project.

At the end of this quarter, Mr. Jerry Wiser - the chief process engineer of JWBA, took a job with an equipment and engineering firm in the Salt Lake City. Jerry still maintains his contact with us as an Associate of the company. With regard to the SPX project, Jerry's contribution included the process control and automation of various process units including the 15-stage distillation column and the continuous liquid-liquid extraction column. He also participated in data processing of the microanalysis of the complex hydrocarbon mixtures. All of the works he was involved in are fully functional and well-documented. At this transition stage, his previous duty is fulfilled by other JWBA staff. The current SPX team is well-suited for the upcoming tasks of running the PDU's and preparing samples for introduction to potential partners and buyers.

The dialog with potential industrial partners is continuing. We keep receiving inquires about our pyridine technology, including companies outside of United States. We are also preparing for presentation of a business plan before the Dawnbreaker commercialization assistance program. At the present time, although we can put together a "presentable" package, the lack of manufacturing plan and proof of market assurance (the originally proposed Phase-III work which has yet to be funded) may turn out to be critical for making this project commercial attractive. 


\section{Technical Progress Report}

\section{Objectives for the Quarter were:}

- Continue compound type analysis on shale oil extract fractions;

- Continue investigation of the LLX process to improve overall extraction efficiency;

- $\quad$ Conduct hydrodealkylation of the $>290{ }^{\circ} \mathrm{C}$ shale oil extract fraction;

- Continue industrial contacts and marketing efforts.

\section{Discussion}

\section{Task 8. Separation Development}

Determination of Basic Nitrogen Types We have set up a Mettler D-40 automatic titrator for measuring the basic nitrogen types of the shale oil fractions. The nonaqueous titration was applied to shale oil samples which measures the molar quantity of types exhibiting different neutralization potentials. We have preliminarily used this differences to distinguish between the various types of nitrogen compounds found in shale oil including pyridines, aromatic amines, aliphatic amines, and a miscellaneous group which includes pyrroles, nitriles, amides, and nitrogen compounds with two or more nitrogen atoms. We have analyzed four different shale oil samples and the results have been given in the previous Monthly Report (SPX2-37-96, March 20, 1996).

As indicated, pyridines are the most abundant (well above $50 \%$ ) nitrogen compound type found in shale oil. Since 5-membered ring heterocycles are for the most part too weakly basic to be titrated, we have not yet been able to differentiate pyrroles from the other nitrogen compounds. Analysis of oils for pyrrole, indole, and carbazole content can be done by IR technique and we will perform this analysis next.

Capacitive Sensor for the CLLX Process One of the difficulties we experienced about the continuous liquid-liquid extraction (CLLX) process was the detection of the interface of the two fluids. We attempt to use capacitive sensor to detect the interface in the continuous liquid-liquid extraction process. The capacitive sensors are installed on the outside of glass column to 
minimize the disturbance of the internal process flow, which is critical to the liquid-liquid extraction process. The output of the sensor is a function of the distance between the sensor and interface of the two immiscible liquids as well as physical properties of the two liquids. By fine tuning the potentiometer of the sensor, the output can drastically change as the interface is closer to the sensor. We tested the sensor with mineral oil - formic acid system and found it responded well with the change in position of the interface. However, in the real shale oil - formic acid system, the output was relatively insensitive. By increasing the sensitivity of the sensor, the output became unstable. This could be due to the fact that formic acid dissolves a large portion (over forty percent) of the shale oil resulting in less difference in dielectric constants between the two fluids. We intend to perform more tests with optimizing sensitivity of the sensor and further process the signal output (by filtering noise) such that the sensor can be utilized with the real system.

Other analytical procedure under way includes the preparation of ion exchange columns for acid-base separation of shale oil and its fractions.

\section{Task 9. Conversion Development}

During this period we conducted four THDA experiments in a $300 \mathrm{cc}$ batch autoclave. The purposes of these experiments were to investigate the effect of diluent and the effect of reaction temperature with respect to the coking tendency. The results will provide valuable information for the developing flow process.

Two reaction temperatures of 420 and $440^{\circ} \mathrm{C}$ were selected to perform the THDA. Feed was tested both neat (no solvent) and mixed with solvent. A mixture of $25 \%$ toluene and $75 \%$ methylcyclohexane was used as solvent and one part of solvent was mixed with two parts of the $>290{ }^{\circ} \mathrm{C}$ fraction (by weight). Although solvent is not normally required for commercial operation, it is added to our small scale flow operation for easier handling of feedstock. Therefore, the effect of solvent is studied with the batch process. The detailed results of those batch THDA runs are given in a previous report (SPX 2-35-96, January 19, 1996) and showed that at the presence of solvent the yield of coke decreased whereas the yield of gas increased.

As expected, both gas and coke yields increased as reaction temperature increased. The higher gas yield obtained from the runs with solvent present in the feed oil indicated that the solvent (particularly methylcyclohexane) contributed the majority of the gas formation. Also, the presence of solvent reduced the coke formation, especially at higher reaction temperature. The yield of $<290^{\circ} \mathrm{C}$ fraction is nearly doubled for reaction temperature increased from 420 to 440 ${ }^{\circ} \mathrm{C}$. Note that the coke yield also increased by at least five-fold at higher temperature. These results suggested that the product distribution of the THDA process is strongly related to reaction temperature. Based on our previous experience, other process variables includes residence time, hydrogen to oil ratio, and dispersion of the oil (droplet size) at the reaction conditions. 
Understanding the general relationship of these variables is important to establish a credible cost estimate for a commercial facility.

The GC/MSD analysis of the THDA liquid products showed that the major components of the below $290^{\circ} \mathrm{C}$ fraction are paraffins. Evidently, these paraffins are obtained from the breakdown of the side chains of aromatics or heterocycles of the $>290^{\circ} \mathrm{C}$ polar fraction. This result was predicted from our analysis of the heavy ends and demonstrates that the small-ring, long alkyl chain nature of the heavy ends is an accurate representation of the shale oil in the high boiling regime.

The $121 \mathrm{~m} / \mathrm{z}$ (ionization fragment of tri-substituted pyridines) ion chromatogram of the feed and THDA products showed the depletion of the series eluting later than $368^{\circ} \mathrm{C}$ (or $\mathrm{n}-\mathrm{C} 22$ ) and the production of pyridines eluting earlier than $368^{\circ} \mathrm{C}$ (or n-C22) (as seen in Monthly Report SPX2-35-96, January 19, 1996). This is further evidence of the potential effectiveness of THDA to produce the desired pyridine concentrates. Unfortunately, the amount of sample produced from the batch THDA runs was not enough to carry out further separation of the polar fractions.

In the mean time, effort was made to overcome problems encountered during the flow THDA trials. These problems mainly associated with the sand particles carried over from the shale retorting process. It was resolved by pre-filtering the feed oil through a $40 \mu$ filtering screen and pulse inject hydrogen into the system before oil entering the oil preheater. A successful flow THDA experiment of the $>290{ }^{\circ} \mathrm{C}$ polar fraction was carried out at $520^{\circ} \mathrm{C}$ and $1300 \mathrm{psig}$ hydrogen partial pressure with a calculated gas residence time about three seconds.

The analysis of the solid product showed a $2.2 \%$ yield relative to the shale oil feed. The solid contains $29.4 \%$ ash by weight, which leaves a $1.3 \mathrm{wt}$. \% net coke yield. This is comparable to the coke yield of the one hour batch experiment at $420^{\circ} \mathrm{C}$. The lower coke yield at higher operation temperature is one of the characteristics of the short residence time hydropyrolysis of heavy oils.

The gas yield, according to the analysis of gas composition and calibration with standard gases, is $3.1 \%$ relative to the total feed (including solvents). The information obtained from the batch experiments (see the previous Monthly Report, SPX2-35-96) indicated that majority of the gases were produced from the solvent (methylcyclohexane). The analysis of the gases produced in the flow run indicated that the olefin content was significantly lower than that of the batch experiments. This may result from the benefit of higher hydrogen-to-oil ratio in the flow operation. Low olefins is an indication of a strong $\left[\mathrm{H}^{*}\right]$ effect. The solids and gas yields are consistant with our earlier experience with low/no coke yield and low hydrogen consumption when hydropyrolyzing residual feedstocks. :

The analysis of the liquid products, which represented $94.2 \%$ of the feed, showed less material boiling above $440^{\circ} \mathrm{C}$ than that of the feed oil. On the other hand, the yield of the $<290$ ${ }^{\circ} \mathrm{C}$ fraction was only about 10 percent of the original feed. We believe the process severity needs 
to be elevated in order to improve the $<290{ }^{\circ} \mathrm{C}$ yield. Because the reactor system was adapted from a previous coal hydropyrolysis unit (under the subcontract with the University of Utah), the opportunity for major modification is limited. We have, nevertheless, installed an additional heater on the oil transit line (between the oil preheater and reactor) and laid additional insulation at the bottom of the main reactor furnace. A heat-up test showed that these improvement has increased the temperature in the main reactor furnace by $40^{\circ} \mathrm{C}$. We will carry out the flow THDA at a more severe process conditions.

\section{Task 11. Simulation and Economics}

The value enhanced products obtained from the SPX technology can be categorized as pyridine concentrates (including quinolines), polar solvents and additives, speciality oils and waxes, and premium refinery feed (low in nitrogen and sulfur). The general suite of primary products and by-products and their anticipated selling price are tabulated as followings:

\begin{tabular}{|l|c|c|cr|}
\hline \multicolumn{1}{|c|}{ Product } & $\begin{array}{c}\text { Quantity } \\
\mathbf{1 0 0 0} \text { s bbl/yr }\end{array}$ & price/bbl & \multicolumn{2}{c|}{$\begin{array}{c}\text { weight contribution } \\
\text { to revenues }\end{array}$} \\
\hline pyridine concentrates & 165 & $\$ 220$ & $\$ 22$ & $35 \%$ \\
\hline polar solvents \& additives & 215 & $\$ 120$ & $\$ 16$ & $25 \%$ \\
\hline speciality oils \& waxes & 330 & $\$ 65$ & $\$ 13$ & $20 \%$ \\
\hline premium refinery feed & 940 & $\$ 22$ & $\$ 13$ & $20 \%$ \\
\hline Subtotal & 1650 & & $\$ 63$ & $100 \%$ \\
\hline
\end{tabular}

For a $5000 \mathrm{bbl} /$ day operation ( $330 \mathrm{day} / \mathrm{yr}, 24 \mathrm{hr} /$ day), the capital investment is estimated to be $\$ 60 \mathrm{M}$ (see the 11 th Quarterly Report, December 1995). The operating cost (including the price of feed stock) is $\$ 43 \mathrm{per}$ bbl, and the projected selling price is $\$ 63$ per bbl. Based on a $\$ 1 \mathrm{M}, \$ 4 \mathrm{M}, \$ 50 \mathrm{M}$, and $\$ 4 \mathrm{M}$ per year investment schedule (assume $100 \%$ equity) and 15 -year straight line depreciation, the internal rate of return (IRR) is calculated to be $27 \%$ yielding a net present value (NPV) of $\$ 65 \mathrm{M}$ at the end of the period. The cash flow analysis is listed as Table 1. The positive value of IRR and NPV indicate that the investment is quite profitable. Figure 1 showed the economic sensitivity analysis of the SPX project, using 5000 bpsd capacity, $\$ 63$ per bbl product value, and $\$ 43$ per bbl operating cost as base values. As seen, the investment is relative insensitive to the capital cost. However, the cost of raw shale shale oil has to be under $\$ 36$ per bbl and the weighted product revenue has to be at least $\$ 53$ per bbl to make SPX project lucrative. 
We use the above economic analysis as a basis for preparing the presentation before the Dawnbreaker commercialization assistance program. Obviously, the projected selling price is largely driven by the most valuable pyridine concentrates. We are performing an updated in-depth market study about the pyridine concentrates at the present time. Ideally, the product development work and the venture planning process should occur simultaneous. Full funding of Phase-III $(\sim \$ 600 \mathrm{~K})$ would greatly enhance our market assurances of the product slate and raise the probability that we would partner with industry for full-scale development. Without Phase- III results, the business plan will be less attractive because there will be greater risks in assuring buyers for the products at the price projected.

\section{Objectives for the Next Period}

- $\quad$ Continue flow THDA of S.O. $>290^{\circ} \mathrm{C}$ polar fraction and analyzing its products,

- Conduct potentiometric titration and IR analysis on S.O. extraction products for basic nitrogen determination and compound type analysis,

- Investigate reaction types (e.g., oxidation, chlorination, and polymerization) of the $<290^{\circ} \mathrm{C}$ shale oil extract fraction in order to obtain higher values products;

- Continue industrial liaison, market evaluation and prepare commercialization business plan. 





Cash Flow Analysis

\begin{tabular}{rrrrrrrrr|}
\hline 11 & 12 & \multicolumn{1}{c}{13} & 14 & 15 & 16 & 17 & \multicolumn{1}{c|}{18} \\
\hline $103,950,000$ & $103,950,000$ & $103,950,000$ & $103,950,000$ & $103,950,000$ & $103,950,000$ & $103,950,000$ & $103,950,000$ \\
$(70,950,000)$ & $(70,950,000)$ & $(70,950,000)$ & $(70,950,000)$ & $(70,950,000)$ & $(70,950,000)$ & $(70,950,000)$ & $(70,950,000)$ \\
0 & 0 & 0 & 0 & 0 & 0 & 0 & 0 \\
$(4,000,000)$ & $(4,000,000)$ & $(4,000,000)$ & $(4,000,000)$ & $(4,000,000)$ & $(4,000,000)$ & $(4,000,000)$ & $(4,000,000)$ \\
$(2,079,000)$ & $(2,079,000)$ & $(2,079,000)$ & $(2,079,000)$ & $(2,079,000)$ & $(2,079,000)$ & $(2,079,000)$ & $(2,079,000)$ \\
0 & 0 & 0 & 0 & 0 & 0 & 0 & 0 \\
\hline $26,921,000$ & $26,921,000$ & $26,921,000$ & $26,921,000$ & $26,921,000$ & $26,921,000$ & $26,921,000$ & $26,921,000$ \\
$(10,768,400)$ & $(10,768,400)$ & $(10,768,400)$ & $(10,768,400)$ & $(10,768,400)$ & $(10,768,400)$ & $(10,768,400)$ & $(10,768,400)$ \\
\hline $16,152,600$ & $16,152,600$ & $16,152,600$ & $16,152,600$ & $16,152,600$ & $16,152,600$ & $16,152,600$ & $16,152,600$ \\
$4,000,000$ & $4,000,000$ & $4,000,000$ & $4,000,000$ & $4,000,000$ & $4,000,000$ & $4,000,000$ & $4,000,000$ \\
0 & 0 & 0 & 0 & 0 & & 0 & 0 & 0 \\
& & 0 & & & & & & \\
\hline $20,152,600$ & $20,152,600$ & $20,152,600$ & $20,152,600$ & $20,152,600$ & $20,152,600$ & $20,152,600$ & $20,152,600$ \\
$85,940,150$ & $106,092,750$ & $126,245,350$ & $146,397,950$ & $166,550,550$ & $186,703,150$ & $206,855,750$ & $227,008,350$ \\
& & & & & & & & \\
$7,769,700$ & $7,063,363$ & $6,421,239$ & $5,837,490$ & $5,306,809$ & $4,824,372$ & $4,385,793$ & $3,987,084$ \\
$27,499,810$ & $34,563,173$ & $40,984,413$ & $46,821,903$ & $52,128,713$ & $56,953,085$ & $61,338,878$ & $65,325,962$ \\
& & & & & & & \\
\hline
\end{tabular}




\section{SPX Economics Sensitivity Analysis}

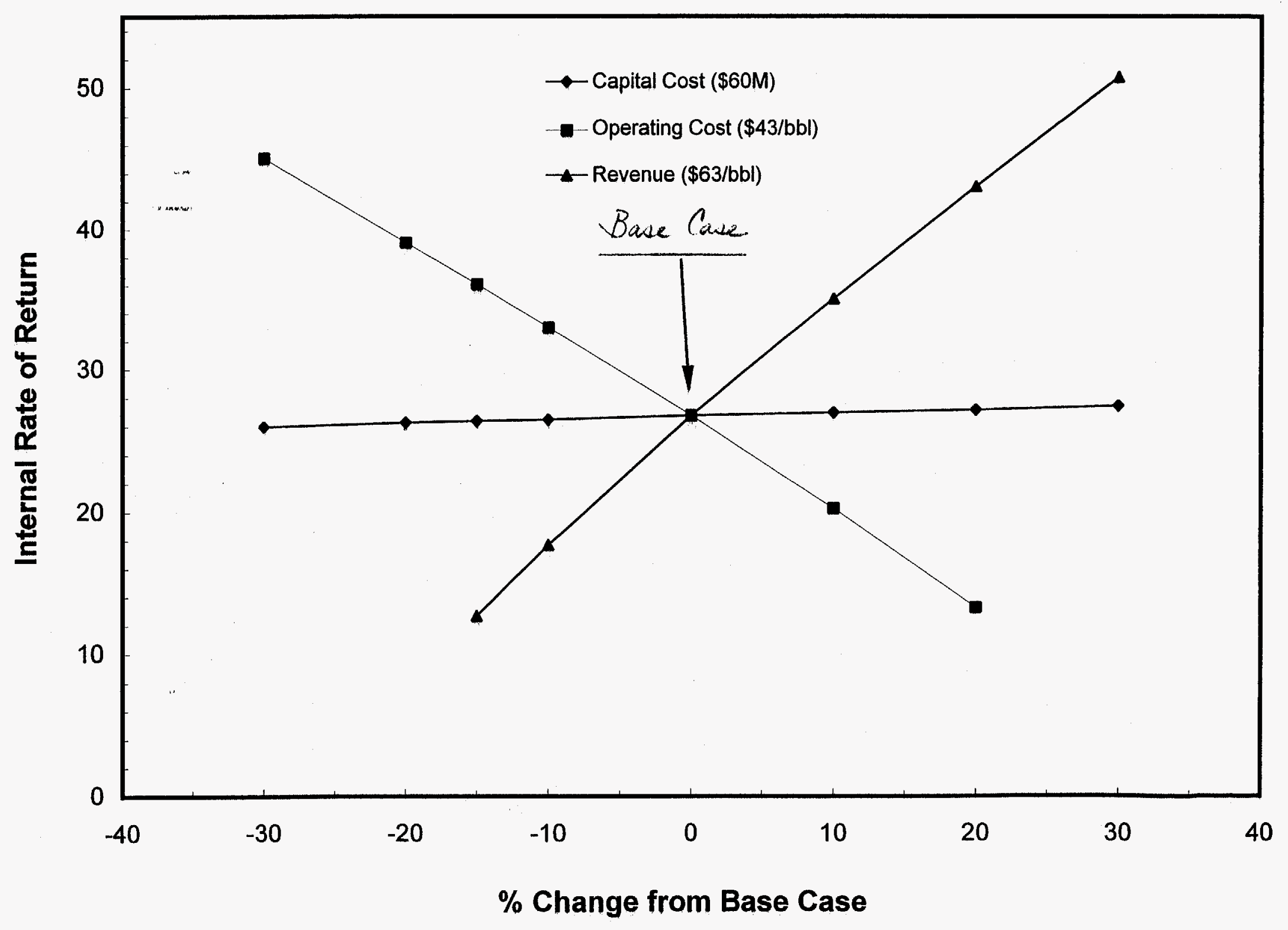

